\title{
La cerámica de etiqueta de las tolas de Japoto (costa de Ecuador)
}

La céramique d'apparat des tolas de Japoto (côte de l'Équateur)

The formal ceramic wares of the tolas of Japoto (coastal Ecuador)

\section{Karen E. Stothert}

\section{(2) OpenEdition}

\section{Journals}

Edición electrónica

URL: http://journals.openedition.org/bifea/3640

DOI: $10.4000 /$ bifea.3640

ISSN: 2076-5827

Editor

Institut Français d'Études Andines

Edición impresa

Fecha de publicación: 1 diciembre 2006

ISSN: 0303-7495

\section{Referencia electrónica}

Karen E. Stothert, «La cerámica de etiqueta de las tolas de Japoto (costa de Ecuador) », Bulletin de I'Institut français d'études andines [En línea], 35 (3) | 2006, Publicado el 02 junio 2014, consultado el 10 diciembre 2020. URL : http://journals.openedition.org/bifea/3640 ; DOI : https://doi.org/10.4000/bifea 3640

\section{(@) $\Theta \Theta$}

Les contenus du Bulletin de l'Institut français d'études andines sont mis à disposition selon les termes de la licence Creative Commons Attribution - Pas d'Utilisation Commerciale - Pas de Modification 4.0 International. 


\title{
La cerámica de etiqueta de las tolas de Japoto (costa de Ecuador)
}

\author{
Karen E. Stothert*
}

\section{Resumen}

El presente ensayo ofrece una descripción de tres clases de cerámica decorada recuperadas en tolas que originalmente fueron ocupadas durante una fase temprana del periodo Manteño en el sitio Japoto (provincia de Manabí, Ecuador). La vajilla decorada con motivos que evocan ancestros y conceptos cósmicos que funcionó en contextos ceremoniales y rituales se interpreta como cerámica de etiqueta. Se discute el papel social, político y religioso de esta cerámica muy difundida y diagnóstica de la cultura de los antiguos manteños.

Palabras clave: cerámica, tola, periodo Manteño

\section{La céramique d’apparat des tolas de Japoto (côte de l'Équateur)}

\section{Résumé}

Cet article décrit trois classes de céramique d'apparat provenant du site à monticules artificiels de Japoto, Province de Manabí, Équateur (phase ancienne de la période Manteño). Les décors et motifs y représentent des ancêtres ou des concepts cosmologiques que l'auteur interprète comme un ensemble de céramique d'apparat qui servait dans des contextes cérémoniels ou rituels. Puis il aborde le thème du rôle social, politique et religieux de cette céramique très répandue et qui peut être considérée comme diagnostique de la culture manteña.

Mots clés : céramique, tola, période Manteño

* Centro de Investigación Arqueológica de la Universidad de Texas (San Antonio). E-mail: stothertk@sbcglobal.net 


\section{The formal ceramic wares of the tolas of Japoto (coastal Ecuador)}

This paper presents a description of three classes of decorated ceramics recovered from the tolas of the site of Japoto (province Manabi, Ecuador), originally occupied in the Early Manteño period. These fine wares decorated with designs that evoke ancestors and cosmic concepts are interpreted as conforming a set of formal wares used in ceremonial and ritual contexts. The social, political and religious roles of this widely used ware, understood as diagnostic of manteño culture, are discussed.

Key words: ceramic, tola, Manteño period

\section{INTRODUCCIÓN}

La cerámica ha sido — desde los albores de su producción hace 5000 años— importante en contextos ceremoniales y rituales. Por medio de técnicas y arte, los alfareros lograron crear un material casi inmortal, duro y milagroso, que brilla, que aparece en muchos colores, que toma formas diversas y que se convirtió en un vehículo vistoso de comunicación muy vinculado a actividades comensales, y por ende de gran valor. En este ensayo se destaca el papel que tomó la cerámica dentro de la comunidad manteña de Japoto, un paradero ocupado en los siglos próximos a 1000 AD1.

El estilo cerámico denominado Manteño-Guancavilca tenía una amplia distribución en la costa del Ecuador desde Bahía de Caraquéz en el norte hasta la provincia de El Oro en el sur, entre 900 y 1532 AD. Los elementos utilitarios de los conjuntos cerámicos varían regionalmente, pero los objetos decorados fueron muy similares desde el norte hasta el sur, evidencia de un comportamiento común, un patrón cultural compartido por numerosos pueblos en el periodo Manteño en la costa ecuatoriana.

Según mi hipótesis, el conjunto cerámico decorado evidencia un protocolo al momento de comer que regía en la vida social, política y religiosa de aquel entonces. En todo el territorio manteño familias acomodadas emplearon la misma vajilla de etiqueta compuesta de objetos cargados de símbolos cósmicos y ancestrales. Los objetos decorados de la gente manteña-guancavilca todavía nos remiten a la organización del universo, al flujo de energía vital, el ciclo de vida y muerte, a las grandes fuerzas femeninas y masculinas, a los grandes procesos regenerativos del cosmos. Los motivos decorativos empleados son los mismos que se presentan en la pintura corporal representada en las esculturas de cerámica que retratan personajes manteños (Guinea, 2004), y los mismos que aparecen en todas las categorías del arte ordinario y esotérico manteño, incluyendo torteros, sellos (pintaderas), sillas de piedra, estelas y arquitectura (Guinea, 2004). Estos elementos decorativos básicos son milenarios y corresponden a los fosfenos percibidos por personas en trance.

Sin entrar mucho en la interpretación de la organización sociopolítica de los manteños, quisiera señalar la importancia de «casas grandes» (entendidas como unidades sociales) en el periodo temprano cuando se inició la construcción de un conjunto de tolas (plataformas de tierra) en el sitio hoy conocido como Japoto. Posteriormente, en los periodos tardíos de la trayectoria manteña, se realizó en muchos sitios la construcción de edificios grandes con cimientos

1 La siguiente discusión se basa en el estudio de una parte de las colecciones excavadas del sitio Japoto (espacio de estudio del Proyecto Manabí dirigido por el Dr. Jean-Francois Bouchard). Agradezco al Dr. Bouchard por la oportunidad de trabajar en el proyecto. Gracias también a Anne Touchard por algunos dibujos. Las procedencias de todas las piezas ilustradas se encuentran en las leyendas de las figuras 3-6. 
de piedra. Este patrón arqueológico, junto con la cerámica, me hace pensar que la familia corporativa fue la unidad principal de la organización social y económica manteña durante varios siglos. Estas unidades compitieron entre sí en un periodo caracterizado por el desarrollo de sociedades más jerárquicas. Últimamente el concepto de la casa o «casa noble» ha recibido mucha atención académica en discusiones del desarrollo de sociedades complejas (Pauketat \& Emerson, 1991; Gillespie, 2000; Webster, 1990; Joyce, 2000; Helms, 1998). La evidencia de Japoto manifiesta el comportamiento de estas casas en la fase temprana del desarrollo de una sociedad que luego en sus fases tardías tal vez llegó a consolidar y difundir una cultura más centralizada y jerarquizada.

A pesar de la existencia de varias entidades étnicas en la costa del Ecuador en el siglo XVI, parece que sus aristócratas, desde Bahía de Caraquéz en el norte hasta la provincia de El Oro en el sur, compartieron durante todo el periodo Manteño la misma vajilla de etiqueta. Por medio de ella, los mayores de familia (es decir, las autoridades o principales) y también los aristócratas regionales expresaron su estatus y destacaron sus funciones socioreligiosas.

Estas unidades —nuestras «casas»— se perpetuaban a través del tiempo y manejaron proyectos sociales, políticos, económicos y religiosos a beneficio del grupo corporativo. Sus esfuerzos tenían el fin de fortificar su cohesión interna y forjar vínculos con otros grupos (afines, otros aliados, súbditos de varias clases y personajes y casas de mayor prestigio y autoridad). Otra meta de gran importancia en las sociedades indoamericanas fue la de mantener la herencia y presencia de los ancestros. Para crear autoridad dentro de la casa y también para ganar prestigio en el mundo de «otros» (fuera del círculo de parientes íntimos) los mayores de las casas desarrollaron estrategias sociales y simbólicas que dependían de su conexión con sus ancestros y con otros espíritus del mundo paralelo. Este patrón cultural está muy difundido en las comunidades indígenas americanas (Helms, 1993; 1998). Esta estrategia fue de mayor importancia entre las élites, ya que los grupos gobernantes se preocuparon de identificarse con la tierra o con otros recursos y crear unidades de parentesco dominadas por personas identificadas con ancestros poderosos, dadores de bienes.

Un aspecto del comportamiento de estas casas fue la actividad comensal, por medio de la cual líderes de varios segmentos sociales lograron distintos propósitos. Los grupos corporativos adoptaron una etiqueta, una cultura de comida, por medio de la cual sus miembros conocían, practicaban y ensayaron sus relaciones sociales. Actividades comensales formales, repetidos en numerosas ocasiones, expresaron relaciones de género, relaciones entre parientes de distintas edades servían para definir el papel de cada persona vinculada a la comunidad.

Comidas regidas por una etiqueta especial (incluyendo convenciones ceremoniales) y cargadas de simbolismo permitieron a algunas personas desarrollar su prestigio y autoridad, y demostrar su carisma, su poder económico, su habilidad política y su espiritualidad. Una dimensión estratégica del comportamiento de la elite es su identificación repetida con las fuerzas del cosmos, con los poderes espirituales, específicamente con los ancestros. Al destacar su conexión con los ancestros, la elite se convirtió en el representante en el presente mundo de los antepasados que habitaron en el mundo paralelo (Helms, 1998).

Se plantea que cada casa grande (entendido como un grupo corporativo) se preocupó de dar de comer y beber a los suyos y a otros en comidas formales en las cuales reforzaron sus vínculos de parentesco y alianza, y a la vez fortalecer la autoridad y jerarquía social de los patrocinadores de la comida (Clark \& Blake, 1994). La vajilla de etiqueta se repetía con poca variación en asentamientos manteños desde el norte hasta el sur durante cientos de años. Para ofrecer una comida ceremonial, los anfitriones tenían que tener cántaros para servir líquidos (siempre pensamos en brebajes alcohólicos como la chicha), cuencos hemisféricos para tomarlos, otros cuencos más para servir la comida ceremonial y compoteras, platos ofrendatorios de más carga ideológica y de más prestigio en el cual servían ciertos brebajes chamánicos y ofrecieron bienes a los ancestros y otros espíritus. 
Las autoridades de las casas y comunidades aprovecharon de una ideología bien difundida en América: en su pensamiento, el problema central de la vida es mantener la fertilidad de plantas, animales, y de la gente. Los seres humanos tienen la responsabilidad de ver por el buen funcionamiento del sistema cósmico, deben promover el flujo de la fuerza vital del mundo terrenal hacia el otro mundo por medio de oraciones, danzas, ceremonias, sacrificios, comportamiento moral, etc. Los adultos de mayor autoridad y los líderes seculares y religiosos son los encargados de los proyectos de mantenimiento del flujo de poderes vitales. La evidencia de su éxito es la abundancia de comida y la fertilidad de las mujeres. Regresando al tema del comensalismo: cada comida servida señalaba el éxito, o a veces el fracaso, de los esfuerzos de las autoridades, de las elites, pero también el protocolo social y las mismas reglas ceremoniales expresaron el estatus y papel social de cada uno de los participantes².

Además, en la ceremonia comensal los temas sociales estaban vinculados con temas religiosos. En el pensamiento indígena la comida y bebida tan asociadas al concepto de bienestar, también servían para ofrendar a los difuntos y especialmente a los poderosos que conformaron el grupo de preciosos antepasados. Dar de comer a los espíritus fue un acto de comunicación primordial en la construcción de relaciones con seres del mundo paralelo. En muchas tumbas se colocaban vasijas elegantes de cerámica que contenían comida y bebida, ofrendadas al muerto que viajaba al otro mundo donde él o ella se convertía en antepasado dador: el ancestro siguió siendo miembro funcional de la casa y de la comunidad de vivos. Esta ideología se plasmó en objetos materiales asociados con actividades sociales. Las convenciones simbólicas utilizadas por los artistas manteños ya existieron desde hace miles de años: a lo mejor todo el mundo reconoció el contenido simbólico de los motivos decorativos repetidos con varias técnicas en las superficies de vasijas, y también en diversos objetos de cerámica, fibra, piedra, metal y concha que aparecieron en las reuniones sociales y rituales.

No tenemos evidencia de la producción de cerámica dentro del paradero estudiado. Nadie conoce la ubicación de los talleres de la producción de la cerámica fina manteña, pero es claro que había comunicación intensa entre los distintos grupos, porque las vasijas, torteros, figurines, sellos (pintaderas) son muy parecidos entre asentamientos y entre regiones.

Solo sabemos que los pobladores de Japoto participaron en unas actividades culturales que definieron la sociedad manteña. Las autoridades o personas principales de cada casa se esforzaron para mantener el bienestar económico, social y espiritual del grupo. Adquirir y emplear ajuares de contenido simbólico debe haber sido una de las metas de los gobernantes familiares.

Todavía no podemos decir si la casa o casas que construyeron las tolas de Japoto fueron de alta jerarquía dentro de la sociedad manteña regional, o no. Es probable que la casa incorporaba personas vinculadas por parentesco y otras afiliadas, y que los miembros ocuparon distintos rangos y posiciones sociales.

La siguiente descripción de tres categorías de vasijas finas utilizadas en la presentación de comidas ceremoniales nos conduce a imaginar aspectos de las actividades de los manteños que habitaron las tolas de Japoto en el periodo Manteño temprano. La cerámica es muy parecida a otros conjuntos contemporáneos recuperados en Los Frailes (sur de Manabí; Mester, 1990), y en la península de Santa Elena, en la provincia del Guayas (particularmente de la fase La Libertad 1; Paulsen, 1970).

2 Los ritos andinos de «asentarse» según protocolos sociales están interpretados por Allen (1988) y McEwan (2003). 


\section{VAJILLA DE ETIQUETA}

En el estilo manteño hay numerosas formas finas, de pasta dura, bien ejecutadas y caracterizadas por una amplia gama de decoraciones. Las formas principales que funcionaron dentro de los contextos comensales y funerarios, y que tienen mayor contenido iconográfico, son cántaros (jarros, vasos globulares con cuellos restringidos y bordes evertidos); cuencos (platos hondos, abiertos o ligeramente restringidos) y los platos de pedestal (compoteras, o vasijas abiertas no muy hondas, descansando sobre pedestales bajos y altos). Las botellas no son muy recurrentes en Japoto ni en otros conjuntos de la fase temprana. Además los alfareros manteño-guancavilca fabricaron otros artefactos de cerámica que constituyen la parafernalia característica de actividades rituales y ceremoniales de aquel entonces: figurines, sellos (pintaderas), torteros, y otros objetos que expresaban ideas sociales y religiosas.

\section{1. Cántaros}

Estas vasijas vistosas funcionaron para contener y servir líquidos. Ya que muchos de estos han sido recuperados en tumbas, se imagina que la chicha fue ofrendada a los muertos para su viaje post mortem. En los documentos históricos coloniales se leen descripciones de la costumbre de los indígenas de ponerse en contacto con sus ancestros y otros espíritus por medio de danza, música, y canto, todo bajo el efecto de brebajes alcohólicos y de otros ingredientes psicotrópicos. En la figura 1 se aprecia una acuarela del siglo XVIII donde son representados danzantes indígenas del norte del Perú durante una fiesta de cosecha (fig. 1). Los danzantes reciben chicha brindada por un agricultor con un decantador en la mano (Martínez-Compañón, 1978: E167).

\section{1. 1. Pulido y bruñido}

Fragmentos de cántaros decorados aparecen en casi todos los contextos excavados en Japoto. Los cántaros se caracterizan por sus superficies pulidas y por ende son vasijas extraordinarias debido al esfuerzo necesario para crearlas, y por el hecho de que el brillo está vinculado con la fuerza vital que anima el universo (Saunders; 1998; 1999), la fuerza llamada k'ulel (soulforce) entre los antiguos Maya (Schele \& Mathews, 1998: 4850). Es posible que el contraste entre zonas bruñidas y otras sin brillo (matte) evoque la idea de la transformación de lo ordinario en lo espiritual.

El bruñido es la técnica decorativa más recurrente en Japoto, y por medio de ella se crean zonas, bandas y patrones de líneas brillosas desplegados de tal manera que plasman aspectos de la ideología de la gente que los fabricaba y utilizaba. En los casos de los cántaros más sencillos, los hombros de la vasija están por lo menos pulidos entre la coyuntura con el cuello y el punto de diámetro máximo. A veces la mitad inferior de los cántaros globulares y carenados queda alisada, sin brillo, pero adornada por líneas bruñidas: rayas onduladas y en forma de zigzag, sello de la fuerza del mundo paralelo.

Las zonas principales de la decoración incluyen el interior del borde, el exterior del cuello/gollete y los hombros de la vasija donde se presentan motivos bruñidos, incisos o grabados, o ejecutados con la técnica negativa. Algunos tiestos se ven con

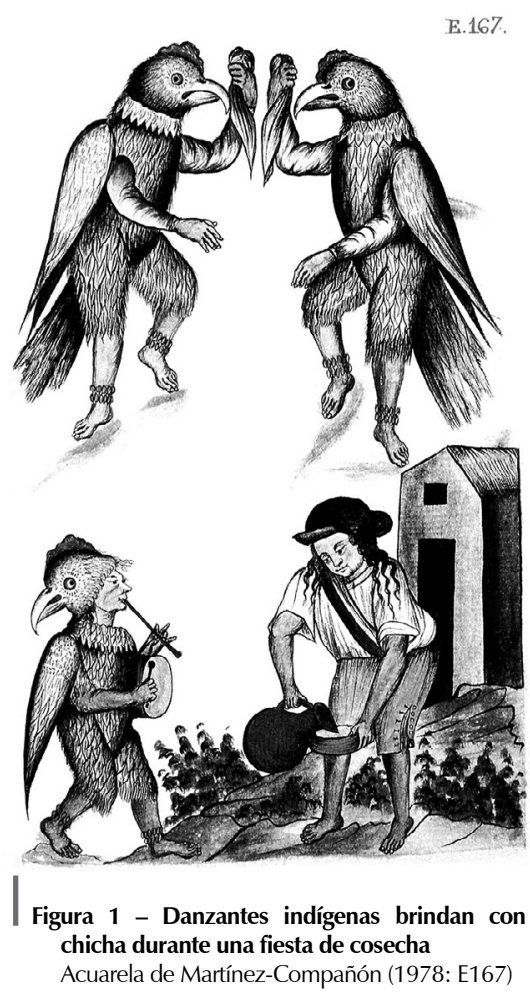


huecos taladrados, posiblemente evidencia el deseo de mantener la funcionalidad de una valiosa vasija, tal vez una reliquia de familia. Ya que el interior de la boca del cántaro recibió mucha atención artística, se puede imaginar que el campo circular se entendía como un mapa del cosmos, y en el centro un portal, un conducto material y metafórico que evoca la idea de comunicación chamánica. Los diseños sirven para llevar el ojo al centro, y para pensar en la vitalidad y complejidad del universo (fig. 2b). En esta figura se representa un campo de diseño relativamente completo: el plan consiste en la repetición de dos paneles contrastantes, con sus rayas limítrofes, que forma una composición de cuatro partes correspondiente a la cuatripartición del cosmos, fundamental en la ideología amerindia, y presente en estilos anteriores de la región manteña.

La composición del diseño de las vasijas - típicamente- se basa en unos campos complementarios: los paneles de líneas onduladas bruñidas se presentan a lado de los de bandas paralelas pulidas (figs. 2b, c). Aparentemente este contraste dual es fundamental, y se repite mucho no solo en las vasijas de Japoto y otros asentamientos domésticos, sino también en los diseños más complejos en piezas mortuorias de alto prestigio.

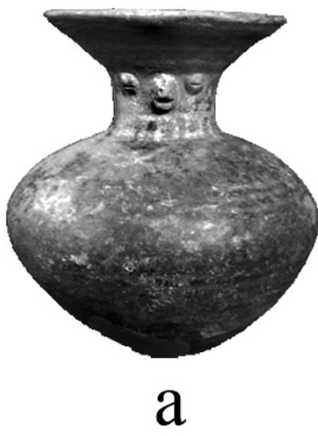

Figura 2 - Cántaros

a. Vasija manteña (Museo de Antropología y Arte/Guayaquil, GA 3-1715-80)

b. Bordes de Japoto con decoración bruñida (J8 Unidad A, Nivel 40-50)

c. Bordes de Japoto con decoración bruñida (J5 TB Nivel 120-140)

Basándose en las interpretaciones de símbolos del arte de varias culturas americanas, se puede imaginar el significado general de los motivos representados y de su organización dentro de los campos de diseño. En las figuras 3-6 se aprecian algunos de los motivos recurrentes en la cerámica manteña: líneas, rayas y bandas radiales, expresiones de poder y espiritualidad (como las plumas que salen del sol o las líneas que emanan de la cabeza del chamán en representaciones indoamericanas); el reticulado que representa la interacción de elementos; volutas y líneas onduladas evocan movimiento, respiración, poder; zonas escalonadas señalan montañas, paisajes sagrados y míticos en la iconografía indígena americana; y listones de puntos y puntas demarcan límites entre las distintas esferas espirituales. Estos motivos sencillos entraron en la iconografía americana hace miles de años, y son los mismos fosfenos que se presentan y huyen cuando uno entra en trance al ingerir sustancias psicotrópicas: representan una visión del mundo paralelo, el de los espíritus y de la fuerza vital.

Estos motivos comunican de manera esquemática la estructura del cosmos, con sus distintos niveles y las fascinantes líneas limítrofes (que desafían a los chamanes viajeros), la cuatripartición del cosmos, la armonía entre fuerzas complementarias (masculina y femenina, vida y muerte, 


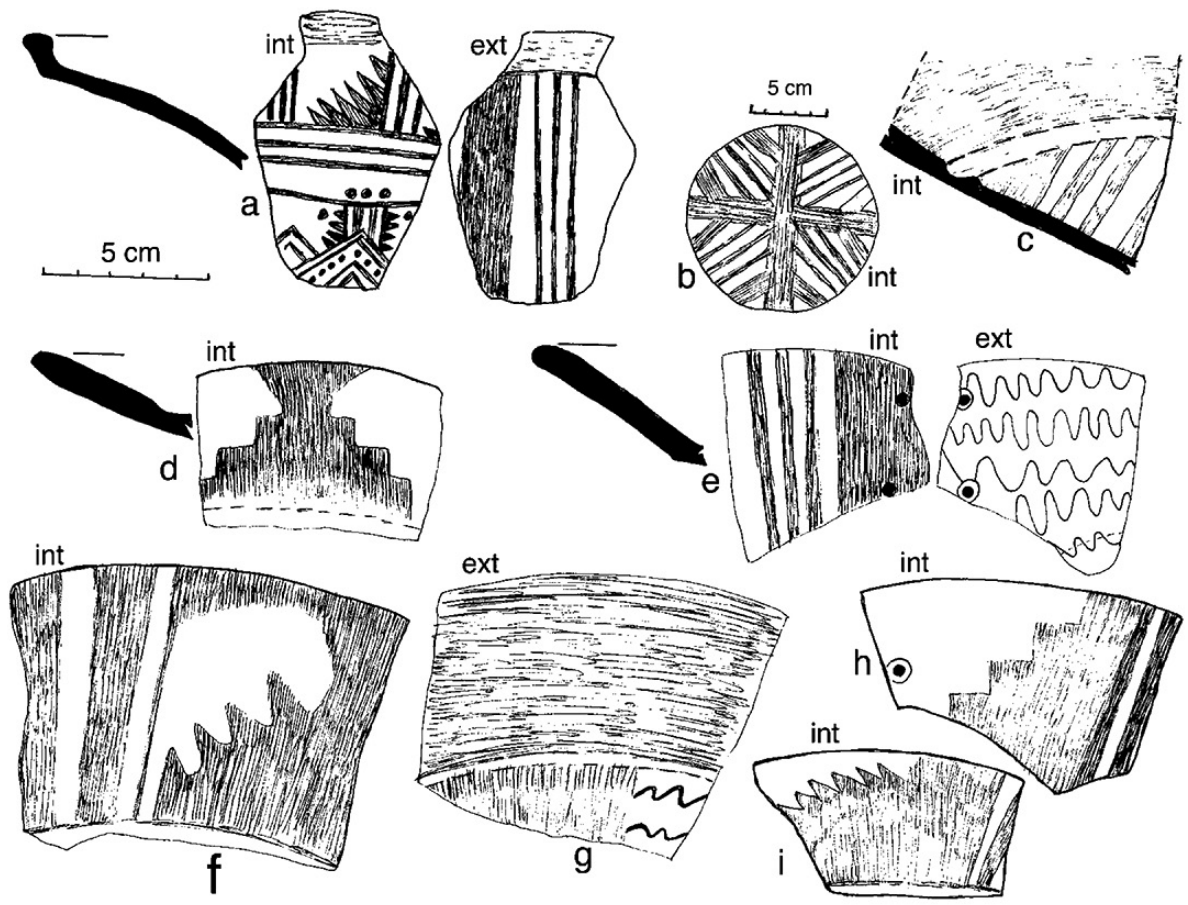

Figura 3 - Cántaros y sellos de Japoto (escala variable)

a. Tiesto con motivos negativos, puntos rojos en nubes de color negro (J2, Zanja 1, Nivel 220-240 cm)

b. Tiesto con motivos negativos, puntos rojos en nubes de color negro (J6, «L», Nivel 1, 0-20 cm)

c. Borde con motivo grabado, color negro ahumado sobre fondo amarillo, con hueco taladrado (J5 TB ext Nivel $40-60 \mathrm{~cm}$ )

d. Borde con motivo grabado, interior negro pulido, ahumado sobre amarillo (J5 TA P4 Nivel 8)

e. Tiesto de cuerpo con motivo grabado sobre engobe rojo pulido (J5 TA ext Nivel 20-40 cm)

f. Borde con motivo grabado, negro ahumado (J3 PZ Capa 1, 0-13)

g. Cuerpo con motivo grabado sobre marrón pulido (J3 PA N.3)

h. Borde con patrón bruñido, negro pulido (J4 Pozo 2, Nivel 1)

i. Cuerpo con motivo bruñido, negro sobre fondo gris-amarillo (J2, Zanja 1, Nivel 180-200 cm)

j. Sello/pintadera de Japoto (J5 TB P1 Nivel 4)

k. Sello/pintadera de Japoto (J5 TB P1, Nivel 7)

I. Sello/pintadera de Japoto (J3 Pozo Z, Capa 1, objeto 4)

$\mathrm{m}$. Borde con cara modelada y dos botones aplicados, interior anaranjado-blanco pulido, exterior gris-erosionado (Cuadrante SE Superficie A) 

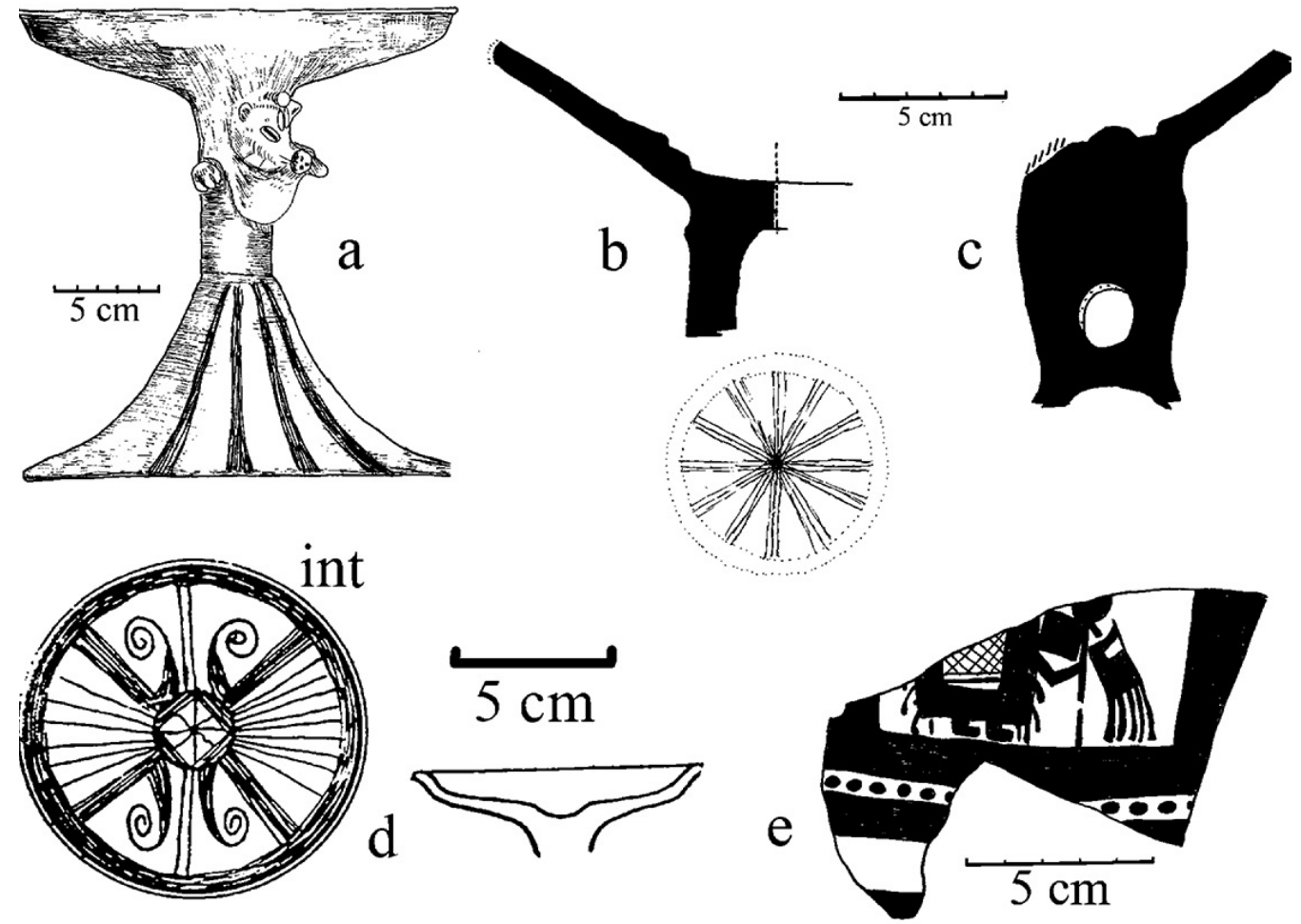

Figura 4 - Compoteras y platos de pedestal (distintas procedencias)

a. Decoración bruñida compleja, negro ahumado sobre gris (J2, Zanja 1, Nivel213 cm)

b. Disposición de bandas y rayas bruñidas en el interior de plato manteño, negro sobre gris ahumado (Mester, 1990: fig. A9)

c. Plato con ranura circular y patrón de decoración bruñida parecida a «b», negro pulido sobre gris (J5, TB Nivel 120-140 cm)

d. Decoración bruñida escalonada, superficie beige pulido con decoración beige claro (J5 TA P4, Nivel 5)

e. Decoración bruñida (color oscuro) sobre fondo gris, con huecos de taladro (J3 Pozo Z, Capa 2)

f. Decoración bruñida, negro ahumado sobre gris matte (J6, Zanja 1, Nivel 4)

g. Zona pulida arriba de la carena con decoración bruñida más abajo, negro ahumado (J6 PC1 borde este 6)

h. Decoración bruñida, gris-negro ahumado (J3, Pozo Z, Capa 9, Rasgo 8)

i. Decoración bruñida, gris-negro ahumado (6 L, Nivel 1) 
La cerámica de etiqueta de las tolas de Japoto (costa de Ecuador)

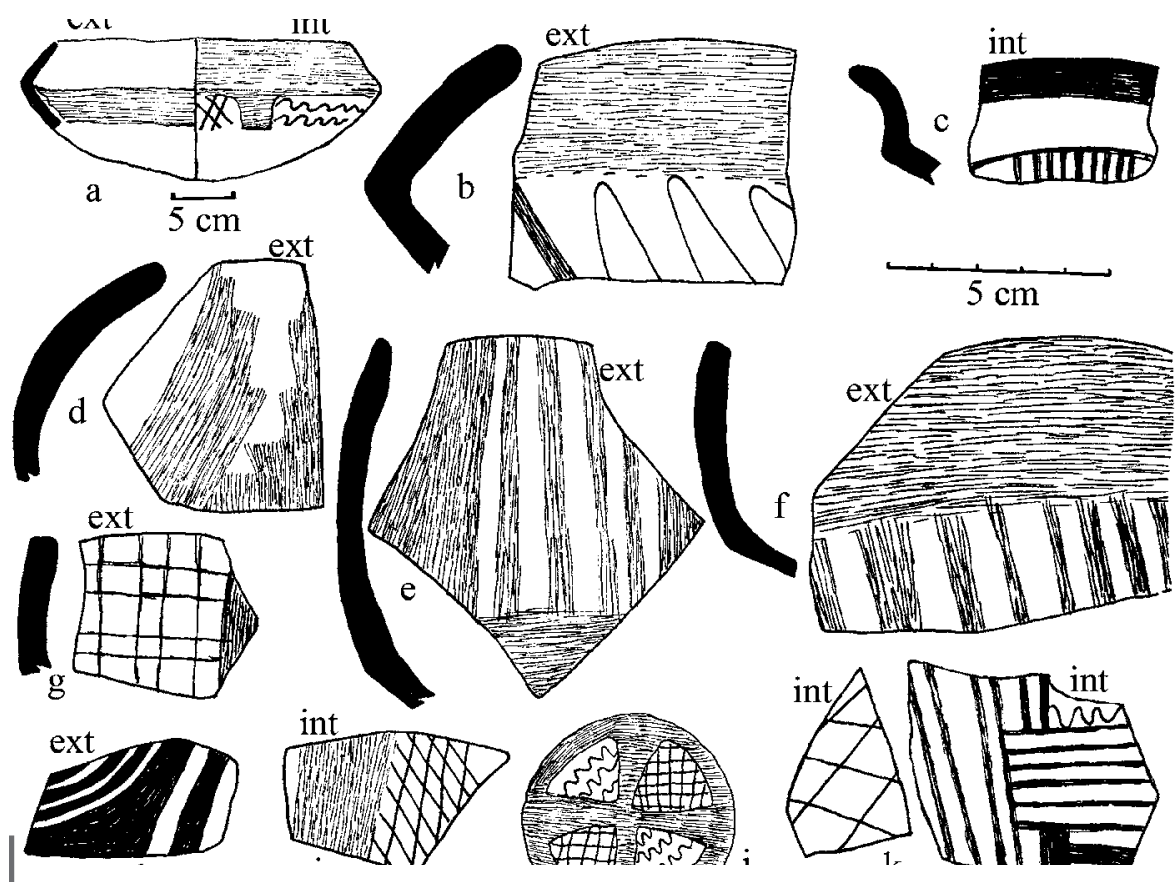

Figura 5 - Pedestales (escala variable)

a. Compotera manteña, color negro ahumado, con decoración bruñida, negro sobre gris (ver detalle «d»); en su exterior un animal modelado y decoración bruñida en el pedestal (Estrada, 1957: fig. 16a)

b. Fragmento de pedestal de Japoto con escalones en su interior, y el centro hundido con un patrón de rayas bruñidas; interior amarillo pulido con nubes y líneas bruñidas de color gris (J6 PC1, Nivel 6)

c. Fragmento de Japoto: interior del plato ahumado; exterior del pedestal amarillo alisado; abultamiento en el centro del plato y hueco bien acabado en el pedestal (J5 TA, P1, Nivel 2)

d. Detalle del interior de la compotera a, con decoración bruñida, negro sobre gris (Estrada, 1957: fig. 16a)

e. Fragmentos del fondo de un plato o cuenco con decoración bruñida en forma de figura humana, color negro sobre gris (J6 PB, Rasgo 1; dibujo de Anne Touchard) 


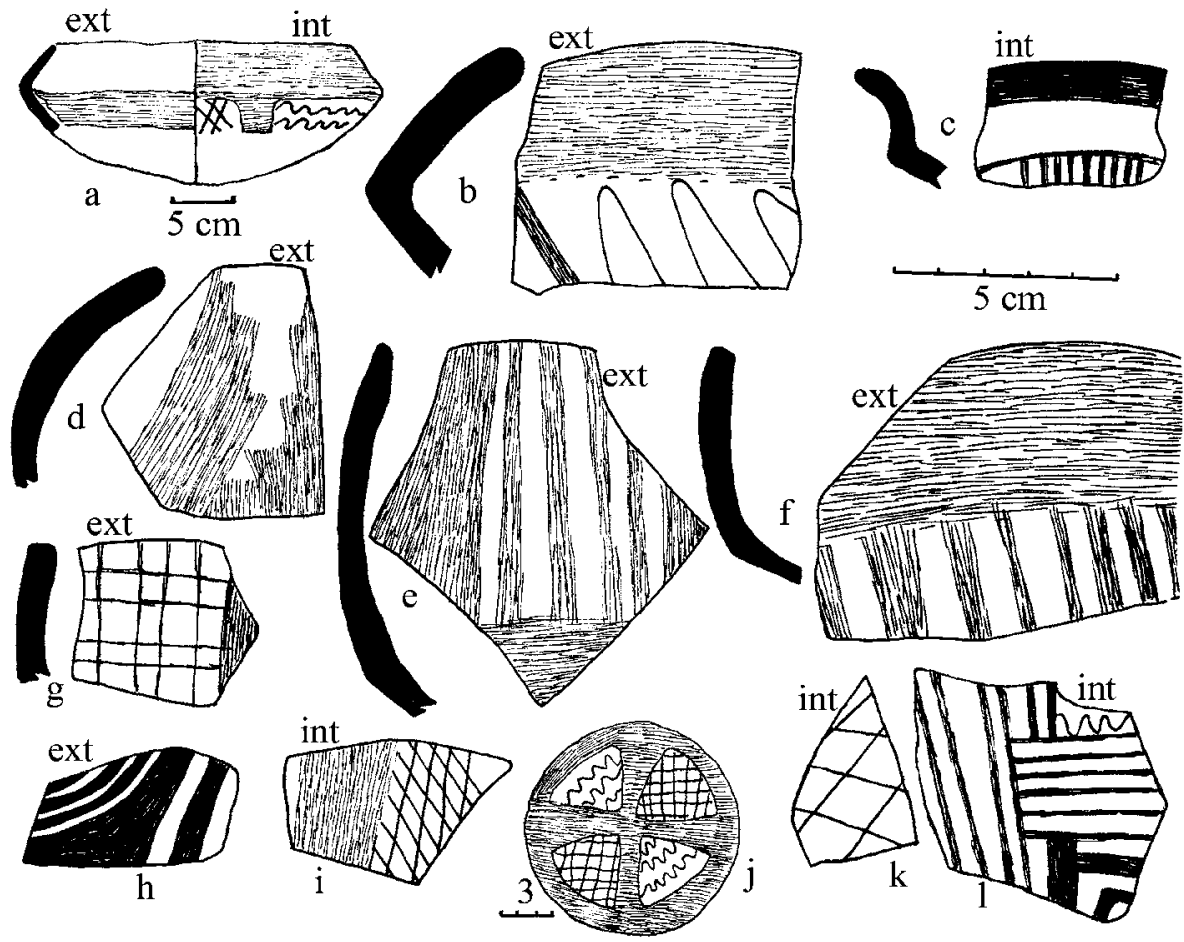

Figura 6 - Cuencos con diseños bruñidos

a. Vasija carenada con zonas pulidas y líneas bruñidas, color negro ahumado (Mester, 1990: fig. A69, $\mathrm{n}^{\circ}$ 44)

b. Borde de Japoto con zona pulida y decoración bruñida, color anaranjado (J3 Pozo Z, Capa 10)

c. Borde pulido y decoración bruñida, negro ahumado (J5 TA ext Nivel $80-100 \mathrm{~cm}$ )

d. Borde con decoración bruñida escalonada, color anaranjado (J3 Pozo Z, Capa 6)

e. Borde con zonas y bandas bruñidas, negro ahumado (J3 Pozo A, Nivel 7)

f. Borde con zona pulida y más abajo rayas radiales bruñidas, negro ahumado sobre gris matte (J3 Pozo Z, Capa 9, Rasgo 8)

g. Patrón de líneas bruñidas color marrón en forma reticulada sobre engobe blanco, con una zona bruñida marrón (J3 Pozo Z, Capa 5)

h. Cuerpo negro ahumado con patrón bruñido sobre gris matte (J2, Zanja 1, Nivel 220-240)

i. Cuerpo anaranjado con patrón bruñido color marrón; el exterior lleva más líneas bruñidas similares (J5 TA P1, Nivel 4)

j. Disposición de decoración bruñida del exterior e interior de cuencos manteños, negro ahumado sobre gris matte (Mester, 1990: fig. A53)

k. Cuerpo con líneas bruñidas, interior y exterior (J2, Zanja 1, 90-110 cm)

I. Cuerpo con decoración bruñida, negro sobre fondo gris (J2 Z1, Nivel 260-280) 
el mundo de arriba y de abajo), y tal vez el concepto de jerarquía. Las fuerzas cósmicas se representan por medio de motivos visualmente activos, como las líneas zigzag. Es importante señalar que los motivos encontrados en la vajilla decorada, se repiten en la decoración de torteros de cerámica y en los sellos/pintaderas (figs. 3j-l) que funcionaron para duplicar motivos sagrados y también como símbolos de identidad en las culturas de la costa ecuatoriana (Cummins et al., 1996; Estrada, 1959; Saville, 1910: Plates LXXVIII, LXXIX).

$\mathrm{Mi}$ argumento es que los individuos patrocinadores de las reuniones ceremoniales se asociaban con fuerzas cósmicas y eventos míticos por medio de la iconografía de los objetos utilizados en las actividades rituales y festivas. Uno imagina que la pintura corporal en los festines de los manteños y también los tejidos llevados por los anfitriones replicaron los mismos motivos vinculados a la cosmología y mitología de los manteños. Los sellos de Japoto presentan motivos que se repiten en nuestra vajilla de etiqueta, en la cerámica prestigiosa de la colecciones de los museos, y en el arte lapidario, las sillas y estelas asociadas a los templos manteños en el gran centro religioso de Cerro Jaboncillo (Saville, 1907; 1910; McEwan, 2003). Al identificarse con esta iconografía manteña, individuos y familias señalaron su participación en el sistema sociopolítico promovido por la elite.

\section{1. 2. Rojo y negro}

La cerámica fina de Japoto destaca por sus colores. Por ejemplo, el color rojo fue importante en la creación de algunas vasijas extraordinarias: en el pensamiento indígena americana el rojo es el color de vida y sangre, y se asocia con el principio femenino. Este color se relaciona en todas partes con protección espiritual. En muchos grupos, como paso previo a la participación en ritos, uno se pinta de rojo, y las preciosas ofrendas fueron saturadas de polvos rojos antes de sacrificarse.

En cambio, la cerámica más emblemática de los manteños es la negra ahumada y pulida. En las colecciones de museos se encuentran muchas vasijas muy finas con decoración bruñida de color negro. En nuestras colecciones excavadas de Japoto la mayor parte de las vasijas con decoración bruñida tienen superficies ahumadas, de color negro pulido sobre gris matte, pero en general el negro-gris no es el color dominante de la cerámica fina de Japoto durante la fase manteña temprana.

Hay que hacer hincapié en la idea que el artefacto negro ahumado es extraordinario por los requisitos técnicos de su cocción. El proceso de hacer elegantes superficies negras había existido por miles de años, pero no fue muy popular en el periodo anterior a los manteños. Parece que la cerámica negra ahumada se puso a la moda en el periodo Manteño. Aparentemente fue adoptada por los aristócratas regionales en la misma época que esa cerámica logró popularidad entre los señores de la zona de Lambayeque, en el norte del Perú durante la fase Sicán. La producción de cerámica diferente de los estilos anteriores servía para señalar la posición especial de la élite ascendiente de los manteños y para destacar la importancia del nuevo Señor de Sicán (Shimada, 1995).

Los colores rojo y negro fueron (y son) de gran significado para los indígenas americanos, y en algunas tumbas manteñas, se recuperaron pares de vasijas, una roja y la otra negra, sugiriendo así aspectos complementarios del pensamiento americano (como femenino y masculino, o terrenal y celestial). La «pintura negativa», una técnica especial que requiere una serie adicional de pasos en su proceso de manufactura, también resulta en vasijas extraordinarias. En la superficie de estas vasijas se crea un juego entre dos colores: en Japoto diseños rojos asoman misteriosamente dentro de una nube negra. Esta clase de decoración especial es apta para expresar ideas esotéricas. En Japoto la técnica se empleaba para crear constelaciones de puntos, listones con puntos, rayas y zonas escalonadas de rojo y negro (figs. 3a, b). Estas misteriosas manchas evocan los fosfenos asociados con los trances chamánicos. Los diseños negativos, que se repiten en los hombros y bordes de los cántaros y en los platos de pedestal, también son recurrentes en La Libertad y Los Frailes (Paulsen, 1970: fig. 9H; Mester, 1990: fig. A40). 
La técnica del decorado negativo fue empleado para jugar con los colores rojo y negro y a la vez presentar motivos cósmicos, rayas y conjuntos de puntos esotéricos — que probablemente evocaron algún concepto bien entendido hace 1000- . Estas vasijas descomunales, al igual que las bruñidas, evidenciaron la inversión de mucha destreza y mayores esfuerzos artísticos que servían para destacar el prestigio del patrón de reunión social, y reiterar su identidad como intermediario cósmico.

\section{1. 3. Representación gráfica de seres míticos}

Otra área de simbolismo amerindio es la que evoca el tema del flujo de fuerza vital y la reproducción de plantas, animales y humanos por medio de efigies de animales y de seres antropomorfos, incluyendo ancestros dadores y otros espíritus más. La interpretación de los numerosos figurines manteños recuperados en Japoto está fuera del alcance de este ensayo, pero la cerámica de etiqueta también lleva representaciones de seres especiales.

Algunos cántaros de Japoto evidencian la ejecución de motivos grabados a la manera de grafiti en el interior de los bordes de los cuellos acampanados y en los cuerpos de los cántaros (figs. 3c-g). Hemos identificado unos felinos o dragones (por sus características surrealistas), un venado con astas, un hombre con algo en la mano y unos dibujos abstractos. Este grupo de motivos está unificado por el tratamiento de los cuerpos que se llenan de líneas en forma reticulada. Es posible que estos seres sean protectores míticos evocados en contextos domésticos o ceremoniales; pero igual, podrían haber funcionado como símbolos de algún grupo social, sello del dueño del cántaro, o representaciones vinculadas con alguna celebración específica. Los seres no realistas evocan memorias de los monstruos (o dragones) que fueron representados en el arte religioso Bahía del periodo anterior. Estos seres tal vez surgieron del folklore regional. En todo caso, los motivos grabados (como escritura o dibujo) en la superficie de los cántaros evocan temas especiales, tal vez personajes míticos. No hay evidencia de grabados parecidos en Los Frailes, pero algunos fueron recuperados en La Libertad (Bushnell, 1951: fig. 42J).

\section{1. 4. Cántaro de cara-gollete}

Algunos cántaros de Japoto son representaciones de un cuerpo humano o animal: el gollete lleva el rostro, el borde sirve de tocado, y en los hombros de algunas vasijas se presentan los brazos de algún ser que a lo mejor es un ancestro u otro personaje mítico (figs. 2a, c; 3m; 7a, b). En estos casos el artista antiguo jugó con la idea de la fertilidad de los ancestros dadores (o de un dios creador), enfatizando sus cuerpos como fuentes de la bebida sagrada, ingrediente indispensable en las ceremonias llamadas (despectivamente) «borracheras».

Hay que destacar que las caras del conjunto de Japoto son muy variables e indican que el estilo Manteño Temprano de Manabí Central permitió una variedad de expresiones. Algunos de los rostros son humanos, otros representan animales o seres surrealistas. Típicamente el perfil de la cara se destaca por su mentón u hocico, que sobresale del cuello de la vasija. Algunas caras son retratos realistas realizados en cerámica ahumada con superficies de color negro, vislumbrando los retratos clásicos del estilo manteño con narigueras, aretes y labretes. Otros son muy estilizados: los rostros a veces se reducen a unos pocos elementos (pars pro toto). En muchos casos el enfoque de atención es una tremenda nariz con un ornamento de dos lóbulos (fig. 7a): desde periodos remotos las narigueras sirvieron como marcas de estatus en la sociedad de los vivos y entre los ancestros.

El modelado de las caras se logró por medio de diversos tipos de pastillaje y aplique. En la figura 7a se aprecia una de tipo recurrente: el fragmento demuestra el uso de bandas bruñidas radiantes en el cuello del cántaro arriba de la cara, tal vez señalando el estatus espiritual del ser retratado. En contraste, el rostro presentado en la figura $7 \mathrm{~b}$ es muy simple: una cara dulce 

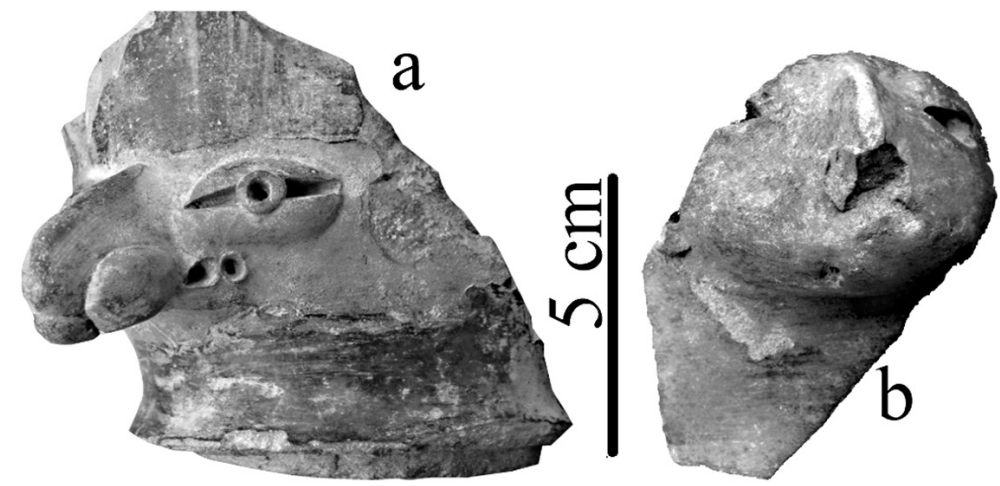

\section{| Figura 7 - Cara-gollete}

a. Tipo de rostro modelado, color negro ahumado (J4 Pozo 1, Nivel 8)

b. Tipo rostro sencillo, con arete, color rojo (33, Pozo A objetos, Nivel 1)

de color rojo que tal vez representa otra clase de ser mítico. Otro tipo de cara se encuentra en una vasija de borde evertido, que podría ser cántaro o plato. En la figura $3 \mathrm{~m}$ se observa una cara minimalista con dos apliqués en la frente: estos son recurrentes en el estilo manteño y seguramente servían para identificar el ser representado.

No sabemos si los personajes retratados en los cántaros de Japoto son sacerdotes, aristócratas, ancestros, seres míticos o deidades manteñas, pero es seguro que en contextos familiares, aún en casas de familias locales de jerarquía menor, fue importante la evocación de estos seres durante el acto de hacer libaciones. La cara estilizada da vida a la vasija, evoca un espíritu animal o un personaje mítico, tal vez uno de los antepasados con el que el anfitrión y su familia se identifican.

Se observa una variedad de cara-golletes en nuestra muestra de Japoto, y la misma selección se presenta en las colecciones de Saville (Saville, 1910, Plate CII: 1-2, 4-7; Plate LXXV: 1-6; Plate LXXVI: 4) y entre los materiales de La Libertad (Bushnell, 1951: figs. 42-43), pero las carasgolletes son escasas en Los Frailes (Mester, 1990: fig. A44). Estas vasijas tipo cara-gollete son las predecesoras de las vasijas retrato más sofisticadas y formales de las fases posteriores en Manabí (Guinea, 2004; McEwan, 2003). En colecciones de piezas en museos se reconocen vasijas tardías que llevan rostros estereotipados, algunos hechos en moldes del tipo «mascarón» (Bushnesll, 1951: figs. 42e, g, h ).

Los golletes con rostros se recuperan frecuentemente como artefactos sueltos, desprendidos de los cántaros, con sus filos amolados. El reciclaje de estos objetos señala que el valor de la cara persistió después de la destrucción de la vasija original. El objeto (con el rostro conservado) luego continuó en servicio como ofrenda, talismán, o quizás como una base anular portátil. Es de hacer hincapié en una idea muy difundida en América: los objetos tienen poder. El artista que produce un artefacto que emana espíritu está no solo expresando este concepto, sino materializándolo. Objetos como piedras llamativas, minerales brillosos, pedazos de concha Spondylus, figurines y fragmentos de cerámica con iconografía espiritual, tienen todos la capacidad de proteger, curar y llevar mensajes al otro mundo. Parece que los cántaros de cara-gollete enteros o fragmentados, igual que los figurines, funcionaron como objetos de poder en ritos y se ofrendaron en actos votivos3.

3 En la sierra ecuatoriana existe la costumbre de conservar los fragmentos de figurines antiguos porque son talismanes (cushi): objetos de poder que traen «buena suerte o ventura» (Holm, 1970). En la costa, la gente manteñaguancavilca modificó los mascarones desprendidos de las vasijas para luego enterrarlos en pozos rituales en la península de Santa Elena. Bushnell ilustra varias de estas caras recuperadas en La Libertad (1951: figs. 42g, h). En Japoto algunos mascarones aparecen sueltos, pero solo en la superficie del sitio. 
En resumen, los cántaros de Japoto son expresiones materiales que evocan seres míticos y ancestros. Los alfareros produjeron objetos hermosos y poderosos manipulando color y motivos bruñidos, pintados, grabados y modelados para comunicar ideas espirituales y políticas. Antiguamente estos recipientes llevaban su carga de chicha junto con su carga simbólica.

\section{2. Platos sobre pedestales (compoteras de doble campana)}

Estas vasijas conforman otra categoría muy prominente en la vajilla de etiqueta y se presentan frecuentemente en tumbas. Deben haber servido para ofrendar a los espíritus, pero también es posible que las reglas sociales especificaron que ciertos tipos de comida fueran servidas en estos platos sobre pedestales. Tal vez las distintas formas corresponden a diferentes comidas: una para tamales, otra para pescado asado, otra para guisos picantes o compotas dulces, etcétera. Son diversas, muy adornadas y muy recurrentes en muchos contextos arqueológicos en Japoto.

En toda América, y hasta la fecha, los sacerdotes indígenas se remiten a las cuatro direcciones cardinales y luego al centro, un punto de significado especial, donde las fuerzas cósmicas se juntan, donde se abren portales, donde se hacen sacrificios. En algunas tradiciones indígenas el plato ofrendatario es un artefacto principal en actos de comunicación con el mundo de los espíritus (Schele \& Mathews, 1998: 48-50). En la práctica, la representación de un universo cuatripartido en un campo como el interior de un plato bruñido configura la forma de un cruz: se ve un axis mundi, el arbol místico de la religión indígena americana (figs. 4b, 6j).

La decoración bruñida de los platos de pedestal de Japoto es similar a la de Los Frailes y de Santa Elena (Mester, 1990: figs. A2, A3, A.9; Paulsen, 1970: fig. 9A), y en muchos de estos el diseño se enfoca en el centro del plato. Algunos dan énfasis en una serie de círculos concéntricos: el borde carenado o aplanado de la vasija es un círculo frecuentemente pulido, creando así un marco brilloso para el diseño trazado adentro. Al interior del borde se encuentra un campo circular típicamente dividido en cuatro paneles que en la iconografía indígena americana corresponden a las cuatro direcciones cardinales, con sus significados distintos, sus colores particulares, sus espíritus y animales y sus categorías sociales asociadas (Boone, 1992: fig. 1 y su interpretación).

El gesto de señalar los cuatro puntos cardinales y el regreso repetido al centro forman una cruz que aparece en las composiciones de los interiores de las vasijas de etiqueta (figs. 4b, 6j). A veces una ranura o reborde cerca del centro del plato señala la zona central donde se encuentra una concavidad circular decorada con otros motivos bruñidos (figs. 5b, d) o un abultamiento circular (como un ombligo) en el epicentro, encima del vacío en el pedestal que apoya el plato (fig. 5c).

La iconografía de los platos en Japoto es muy similar a la de los cántaros y cuencos. No se recuperó ningún plato entero, pero los fragmentos de bordes presentados en las figuras 4 y $5 d$ llevan motivos recurrentes: patrones de líneas rectas, reticuladas, onduladas y en zigzag; bandas y rayas radiales; zonas pulidas simples y escalonadas; cuadros y círculos concéntricos; filas de puntos. Algunos platos únicos son evidencia del estilo de alto prestigio contemporáneo con la ocupación de Japoto. Los motivos en estas pocas vasijas extraordinarias son los mismos que aparecen en las pintaderas y en la cerámica funeraria representada en los museos de Ecuador. El significado de la serie de puntas (parecida a una cordillera o las plumas del ala de un ave) que es un motivo prominente en todas las categorías del arte manteño (figs. 3j; 4a, f, i) no es claro, pero, como en el caso del motivo escalonado, este diseño también evoca paisajes sagrados y funciona a veces como un lindero entre distintos estratos del cosmos (ver motivos limítrofes en Saville, 1910, Plate LVI: 2). En la muestra de platos de Japoto observamos un solo ejemplo de una representación antropomorfa: el personaje aparece elaborado con la técnica del bruñido en la superficie de un plato (fig. 5e): el personaje, enmarcado en una composición bruñida compleja, se encuentra cubierto de atavíos y aparentemente lleva parafernalia para alguna actividad. Una figura parecida se presenta en un sello ilustrado por Estrada (1959: 27). 


\section{2. 1. Pedestales}

Muy recurrente en nuestras colecciones son los fragmentos de pedestales, aunque se confunden con los bordes acampanados de los cántaros. Los platos descritos arriba descansaron sobre soportes, pero no sabemos cual pedestal corresponde a cual plato. Sin embargo, es claro que el pedestal intensifica la importancia del plato decorado, enfatizando la idea de que el centro del plato es la boca del conducto comunicador que da acceso al mundo paralelo. El centro del plato, con su fondo hundido y su decoración bruñida especial (figs. 4c, 5b, d), está justo encima del pedestal. La decoración exterior de los pedestales no deja lugar a dudas: es una estructura cargada de energía cósmica, típicamente adornada por una a superficie bien pulida, líneas bruñidas verticales (radiales), patrones y paneles de líneas onduladas y en zigzag, decoración negativa, y figuras modeladas (fig. 5a). Los fragmentos rotos también señalan otro uso para los pedestales: como los golletes, los filos rotos de la parte superior de los pedestales fueron amolados (fig. 5b), para que la base anular desprendida del plato siga sosteniendo cuencos o platos.

Además, el hueco grande y bien acabado que se presenta en el tronco cilíndrico de algunos pedestales decorados (fig. 4c) me hace pensar en los recipientes ofrendatarios agujereados de los muisca que servían de receptáculos para semillas en los ritos de fertilidad (Falchetti, 1997: 12-18, foto 10).

\section{3. Cuencos}

Fragmentos de cuencos constituyen solo una fracción de los tiestos diagnósticos en nuestros conjuntos excavados. Sin embargo algunos cuencos, de varias formas distintas, son finos y decorados con motivos cósmicos: estos forman parte de nuestra vajilla de etiqueta (fig. 6). Frecuentemente se nota la presencia de huecos taladrados en los fragmentos recuperados, evidencia del arreglo de unos cuencos de valor especial. Se supone que los cuencos pequeños podrían haber servido para tomar líquidos, y los pequeños y grandes para servir comida. Estas vasijas, especialmente las con decoración bruñida, son descendientes directos de los cuencos de las culturas guangala y bahía (Masucci, 1992: figs. 37-38; Stothert, 1993: fig. 52; Estrada, 1962: fig. 44). Las mayoría de los cuencos son de un solo color (anaranjado, amarillo-blanco, rojo, beige, marrón o negro) y tienen superficies pulidas. Algunos llevan decoración bruñida.

El cuenco más recurrente es de boca restringida, sin cuello, y tiene paredes carenadas (figs. 6a, b). Presenta un interior alisado, a veces pulido en el fondo. En su exterior lleva un engobe de color rojo-anaranjado o blanquecino. Está pulido en el exterior, arriba del punto de inflexión, y lleva, por debajo de la carena, una zona de decoración bruñida, a veces dividida en partes separadas por bandas pulidas (fig. 6b). Esta vasija podría haberse utilizado en actos piadosos, por ejemplo para realizar una especie de brindis, porque su forma permite alzar el recipiente cargado de líquido entre las dos manos hacia el cielo o hacia otra persona, dejando a los celebrantes ver, por un momento, los motivos desplegados por el fondo del cuenco.

Los cuencos abiertos, de formas muy variables (figs. 6c-g), están bien pulidos por dentro y por afuera. Son de varios colores, y algunos están decorados por dentro con motivos bruñidos que brillaban al vaciarlos de su contenido líquido (figs. $6 \mathrm{i}, \mathrm{k}, \mathrm{l}$ ).

Típicamente estos cuencos tienen bandas anchas pulidas en sus bordes, por el interior y el exterior, y más abajo aparecen zonas de decoración bruñida (fig. 6f). A veces se nota que los motivos bruñidos están separados por bandas pulidas, formando una composición cuatripartita con una cruz dentro de un marco circular (fig. 6a, e, i). Este patrón es recurrente en los exteriores e interiores de vasijas de Japoto y de Los Frailes (fig. 6j). Otros cuencos de Japoto están decorados con bandas anchas bruñidas por el lado exterior, y diseños de líneas finas por adentro, entre otras combinaciones y variantes de los mismos motivos asociados con ideas cósmicas en los cántaros y platos ya descritos. 
Aunque nuestros fragmentos son pequeños, dan la impresión de que la pared exterior llevaba siempre zonas de diseños bruñidos divididos en cuatro sectores, en la manera de los platos de pedestal, los cuellos de los cántaros y las bases de pedestales. Los cuencos de Los Frailes y Japoto demuestran el contraste entre zonas pulidas y zonas con decoración más gráfica y viva: esta composición nos remite a las cuatro partes del universo, partición que resulta de la intersección de un eje norte-sur y otro este-oeste y que evocan las fuerzas dialécticas que dinamizan el universo. Una vasija extraordinaria lleva bandas y rayas bruñidas por el lado exterior, y por el interior, una composición compleja de motivos enmarcando una figura antropomorfa con un estandarte en la mano (fig. 5e).

Un grupo de cuencos muy finos de cuerpos compuestos (fig. 6c) incluye algunas miniaturas cuya función ceremonial y mortuorio está reconocida en varias partes de América. Estas vasijas llevan patrones de bandas verticales bruñidas, como las del cuello exterior de los cántaros y los bordes interiores y pedestales de los platos descritos arriba. Estas bandas tienen algún significado relacionado con la ideología indígena: aparecen como elementos importantes en los sellos manteños (fig. 3k) y son motivos de gran antigüedad en la región de la costa.

\section{DISCUSIÓN DE LA VAJILLA DE ETIQUETA}

En resumen, se ha planteado el concepto de una vajilla de etiqueta adornada con motivos abstractos derivados de la milenaria tradición iconográfica de la costa ecuatoriana. Estos motivos están desplegados en composiciones significativas del cosmos. Además, las formas y colores de las vasijas contribuyeron a su funcionalidad como objetos de comunicación. Por medio de la decoración los artistas convirtieron artefactos en portadores de información esotérica: los motivos, las representaciones grabadas y modeladas y varios efectos visuales evocan espíritus, señalan conceptos espirituales, y llaman la atención sobre el papel indispensable de los mayores de familia y los sacerdotes y caciques aristocráticos que se responsabilizaron por el mantenimiento de comunicación con el mundo paralelo, fuente de bienestar.

En la vida cotidiana y ceremonial de los manteños la cerámica de etiqueta junto con otros artefactos (como figurines y sellos) afirmaron la relación entre los vivos y otros seres que desde tiempos originarios han participado en el proceso de crear y mantener el flujo de la fuerzas de vida en el universo. Esta cerámica constituyó un elemento cultural muy recurrente en asentamientos manteños, evidencia de las actividades que construyeron la identidad manteña.

Hay que imaginar que los convidados en las comidas de etiqueta disfrutaron de la comida, el fruto del proyecto económico de la familia anfitriona, y también consumieron unos conceptos diseminados por medio de las actividades ceremoniales. El protocolo de la ceremonia hizo a todos participar en relaciones sociales y en actividades simbólicas: en todo momento recibieron mensajes visuales y auditivos. Por medio de la cerámica cargada de significado ideológico los celebrantes escucharon y vieron, y así recibieron información comunicada por los patrocinadores de la reunión, cuya identidad está involucrada en la comida y en la presentación de ella.

Hasta la fecha las ocasiones conmemorativas se destacan por la presentación de comidas especiales. Por ejemplo, hoy en día en Manabí el «culto a la muerte» está anclado en la historia de la familia (Regalado Espinoza, 2006: 2) y dar de comer a los difuntos y a los vivos es una expresión conmemorativa muy corriente en toda la costa de Ecuador. Actividades comensales que ilustran la relación entre la comida y su simbología, por un lado, y la construcción de lazos sociales, políticos y rituales se realizan en Manabí en las siguientes ocasiones:

«los velorios de muertos y de santos, Semana Santa, la Fiesta de los Difuntos, la celebración de Pedro y Pablo, Navidad, la bajada de los Reyes Magos, otras fiestas religiosas locales, onomásticos, cumpleaños, bautizos, matrimonios, despedidas, bien venidas de familiares». (Regalado Espinoza, 2006: 2) 
Libertad Regalado (2006) dice que hoy en día el compadrazgo se crea por medio de la comida repartida, y la misma autora, citando el cronista Estete, reporta que «la cacica de Portoviejo mantuvo en su regazo y bien atendidos a los españoles por espacio de dos meses, mientras esperaban refuerzos y se reponían de enfermedades» (Regalado Espinoza, 2006: 7), muestra de la responsabilidad de la elite indígena en los albores de la conquista. La misma autora habla de la conexión tradicional entre la comida, la religiosidad y la muerte: las tres están vinculadas en los velorios, actos que «se convierten en verdaderas fiestas que terminan en baile y borracheras, y claro está con la degustación de un tradicional plato». Este fenómeno en Manabí actual trata de un complejo de creencias y actividades que involucran comida, amor, sexo, y jerarquía social. Regalado identifica expresiones de poder económico y de relaciones jerárquicas en los matrimonios y quinceañeros, y al nivel político público, en la celebración de los «presidentes Blanco y Negro de la fiesta de San Pedro y San Pablo en Montecristi» (Regalado Espinoza, 2006: 8-9).

A pesar de las diferencias étnicas en la costa ecuatoriana al final del periodo aborigen, se supone que, entre los manteños, las autoridades de las casas y la elite en general —todo el mundo entendió el uso de ciertos símbolos de poder y estatus: oro, plata, bronce, Spondylus, tejidos finos, ornamentos personales, y cerámica con motivos cósmicos-. Se puede argüir que en las ceremonias locales de los manteños se preocuparon de dar de comer a la compañía y a los espíritus. Estos actos se repitieron en contextos familiares, especialmente en reuniones de la casa o clan, y cuando se reunían comunidades organizadas en un sistema jerárquico.

Además se puede argüir que otra función de la cerámica fue la de dar de comer a los muertos, a los antepasados preciosos, y a otros espíritus y deidades que se evocaron para poder mantener lazos de parentesco — siempre con el propósito de asegurar el bienestar de la comunidad por medio del flujo libre de la fuerza vital en el sistema cósmico-. Esta interpretación encuentra soporte en las costumbres actuales: cuando llega el Día de los Difuntos (Todos Santos) en la costa de Ecuador, muchas familias se preocupan de dar de comer a sus queridos difuntos, a los que visitan una vez al año y que tienen que ser bien recibidos para que luego se vayan felices, dispuestos a mandar lluvias y salud a la gente viva.

\section{Referencias citadas}

ALLEN, C. J., 1988 - The hold life has: coca and cultural identity in an Andean community; Washington, D.C.: Smithsonian Institution Press.

BOONE, E. H., 1992 - Pictorial Codices of ancient Mexico. In: The ancient Americas: art from sacred landscapes (Townsend, R. R., ed.): 197-210; Chicago: The Art Institute of Chicago.

BUSHNELL, G. H. S.,1951 - The archaeology of the Santa Elena Peninsula in southwest Ecuador, 154 p.; Cambridge: Cambridge University Press.

CLARK, J. E. \& BLAKE, M., 1994 - The power of prestige: competitive generosity and the emergence of rank societies in lowland Mesoamerica. In: Factional competition and political development in the New World (Brumfiel, L. M. \& Fox, J. W., eds.): 17-30; Cambridge: Cambridge University Press. 
CUMMINS, T., BURGOS CABRERA, J. \& MORA HOYOS, C., 1996 - Arte Prehispánico del Ecuador Huellas del Pasado: Los sellos de Jama-Coaque; Guayaquil:Banco Central del Ecuador. Serie Monográfica 11. Miscelánea Antropológica Ecuatoriana.

ESTRADA, E., 1957 - Los huancavilcas: últimas civilizaciones prehistóricas de la costa del Guayas; 82 p.; Guayaquil: Publicación del Museo Víctor Emilio Estrada 3.

ESTRADA, E., 1959 - Arte aborigen del Ecuador: Sellos o pintaderas; Guayaquil: Museo Víctor Emilio Estrada.

ESTRADA, E., 1962 - Arqueología de Manabí central, 205 p.; Guayaquil: Publicación del Museo Víctor Emilio Estrada 7.

FALCHETTI, A. M., 1997 - La ofrenda y la semilla: notas sobre el simbolismo del oro entre los Uwa. Boletín Museo del Oro, 43: 2-37; Bogota: Banco de la República.

GILLESPIE, S. D., 2000 -- Rethinking ancient Maya social organization: replacing «lineage» with «house». American Anthropologist, 102(3): 467-484; Arlington: American Anthropological Association.

GUINEA, M., 2004 - Los símbolos del poder o el poder de los símbolos. In: Simbolismo y ritual en los Andes septentrionales (Guinea, M., ed.): 9-50; Quito: Abya Yala; Madrid: Editorial Complutense.

HELMS, M. W., 1993 - Craft and the kingly ideal: Art, trade, and power, 287 p.; Austin: University of Texas Press.

HELMS, M. W., 1998 - Access to origins: afines, ancestros, and aristocrats, 258 p.; Austin: University of Texas Press.

HOLM, O., 1970 - La Cerámica Colonial del Ecuador. Boletín de la Academia Nacional de Historia, LIII (116): 265-278; Quito.

JOYCE, R. A., 2000 - Heirlooms and houses: Materiality and social memory. In: Beyond kinship: Social and material reproduction in house societies (Joyce, R. A. \& Gillespie, S. D., eds.): 189-212; Philadelphia: University of Pennsylvania Press.

MARTINEZ-COMPANON, B., 1978 - Trujillo del Perú, t. 2: E71; Madrid.

MASUCCI, M.A., 1992 - Ceramic change in the Guangala phase, southwest Ecuador: A typology and chronology; Dallas: Southern Methodist University. Tesis doctoral.

MCEWAN, C., 2003 - «And the sun sits in his seat»: Creating social order in Andean culture; Urbana-Champaign: University of Illinois. Tesis doctoral.

MESTER, A. M., 1990 - The pearl divers of los frailes: Archaeological and ethnohistorical explorations of sumptuary good trade and cosmology in the north and central Andes. Urbana-Champaign: University of Illinois. Tesis doctoral.

PAUKETAT, T. R. \& EMERSON, T. E., 1991 - The Ideology of Authority and the Power of the Pot. American Anthropologist, 93: 919-941; Arlington: American Anthropological Association.

PAULSEN, A. C., 1970 - A chronology of Guangala and Libertad ceramics of the Santa Elena Peninsula in south coastal Ecuador; New York: Columbia University. Michigan: University Microfilms Internationa. Tesis doctoral.

REGALADO ESPINOZA, L., 2006 (en prensa) - La manaba actual y su comida milenaria; Manta, Ecuador.

SAUNDERS, N. J., 1998 - Stealers of Light, Traders in Brilliance: Amerindian Metaphysics in the Mirror of Conquest. Res: Anthropology and Aesthetics, 33: 225-252; Cambridge: Harvard University Press.

SAUNDERS, N. J., 1999 - Biographies of brilliance: Pearls, transformations of matter and being, c. AD 1492. World Archaeology, 31(2): 243-257; Londres: Routledge.

SAVILLE, M. H., 1907 - The antiquities of Manabí Ecuador. Preliminary report, vol. 1; New York: Heye Foundation Contributions to South American Archaeology. 
La cerámica de etiqueta de las tolas de Japoto (costa de Ecuador)

SAVILLE, M. H., 1910 - The antiquities of Manabí Ecuador. Final report, vol. 2; New York: Heye Foundation Contributions to South American Archaeology.

SCHELE, L. \& MATHEWS, P., 1998 - The code of kings: The language of seven sacred Maya temples and tombs; New York: Schribner.

SHIMADA, I., 1995 - Cultura Sicán: Dios, riqueza y poder en la costa norte del Perú; Lima: Banco Continental.

STOTHERT, K. E., 1993 - Un sitio Guangala temprano en el suroeste del Ecuador; Washington, D.C.: Nacional Museum of Natural History, Smithsonian Institution; Guayaquil: Museo Antropológico del Banco Central del Ecuador.

WEBSTER, G., 1990 - Labor control and emergent stratification in prehistoric Europe. Current Anthropology, 31(4): 337-366; New York: The Wenner-Gren Foundation. 
Pedidos: IFEA, Casilla 18-1217, Lima 18 - Perú, Tel. 4476070

Fax: 4457650 -E-mail: postmaster@ifea.org.pe

Web: http://www.ifeanet.org

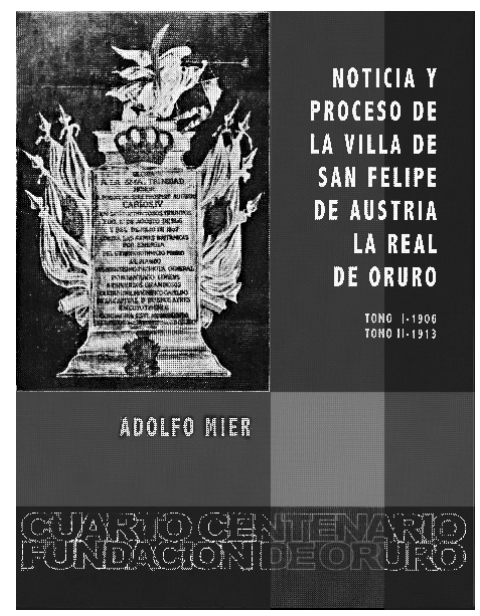

Coedición: Institut français d'études andines (IFEA) - Instituto de Estudios Bolivianos (IEB) Cooperación ASDI-SAREC

Coedición: Institut français d'études andines (IFEA) - Cooperación Holandesa (SNV) Editorial El País

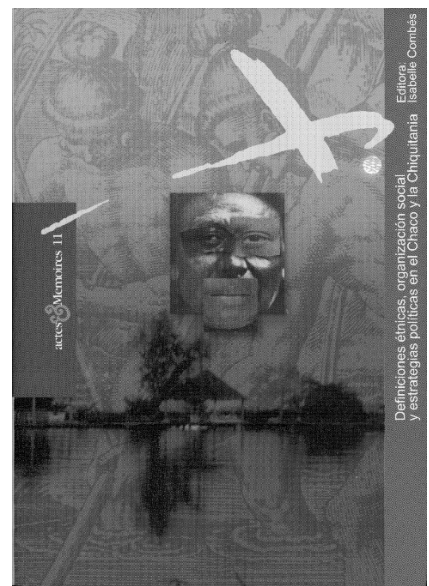

